\title{
Passive Design Strategies for Energy Efficient Buildings in the Arabian Desert
}

\author{
Nedhal Al-Tamimi * \\ Architectural Engineering Department, College of Engineering, Najran University, Najran, Saudi Arabia
}

This study aims to assess passive design features through the extensive modifications of building envelopes to affect the energy efficiency of residential buildings in hot arid climates. In support of the aim of this research, the annual electric energy bill of a typical residential building in Sharurah was collected and analyzed. Then, the DesignBuilder simulation program was used to investigate how different modifications of building envelopes could affect the energy consumption of the residential buildings under common scenarios. Varied thermal insulation, different types of glass, shading devices, and green roof were investigated with this perspective. The simulation results show that thermal insulation can significantly reduce annual energy consumption by as high as $23.6 \%$, followed by green roofs. In contrast, shading devices and glazing system types were fewer superiors. The results also indicate that the effective combination of certain strategies can reduce total energy consumption by $35.4 \%$ relative to the base case $(\mathrm{BC})$ of this research.

Edited by: Audrey Tanguy, Ecole des Mines de Saint-Etienne, France

Reviewed by: Junsong Wang, South China University of Technology,

China

Siamak Hoseinzadeh, Sapienza University of Rome, Italy

${ }^{*}$ Correspondence: Nedhal Al-Tamimi naaltamimi@nu.edu.sa

Specialty section: This article was submitted to Sustainable Design and Construction, a section of the journal Frontiers in Built Environment

Received: 30 October 2021 Accepted: 07 December 2021 Published: 05 January 2022

Citation: Al-Tamimi N (2022) Passive Design Strategies for Energy Efficient Buildings in the Arabian Desert. Front. Built Environ. 7:805603. doi: 10.3389/fbuil.2021.805603
Keywords: energy efficiency, passive design, building envelope, residential building, hot-arid climate

\section{INTRODUCTION}

The hot desert region is facing destructive environmental impacts, such as global warming, climate change and pollution, due to the rapid use of fossil fuels to generate energy, which is then used to enhance the indoor environment of buildings. These challenges have encouraged designers and engineers in the region to adopt passive design strategies to reduce energy consumption, thus helping to reduce the negative environmental impacts. In the last few decades, energy-efficient envelope design strategies have increasingly attracted the attention of researchers around the world (Asfour, 2020). The Kingdom of Saudi Arabia (KSA) has an area of more than 2 million $\mathrm{km}^{2}$, a population of 34.2 million and a density of 15.3 inhabitants per $\mathrm{km}^{2}$. It is one of the fastest-growing countries in the world, with a rate exceeding 2.1\% (GAS, 2019; GAStat, 2019). The annual economic growth rate of KSA is $6.8 \%$. According to the available data for the period between 1980 and 2014 from the Saudi Electricity Company (EIA. Independent, 2014; ECRA, 2014), the annual primary energy consumption per capita of KSA has substantially increased from 3.88 to $9.14 \mathrm{MWh}$, which can be attributed to addressing national needs, especially the growing residential sector. The country has a hot arid climate; consequently, the rapid development and urbanisation of the construction industry have contributed to a national total electricity demand of $77 \mathrm{GW}$ and a total desalinated water demand of 1,912 million $\mathrm{m}^{3}$ in 2014 (ECRA, 2014; GAS, 2019). Nevertheless, studies on energy efficiency in general and energy efficiency in buildings, in particular, have not received much attention in KSA compared with those in similar countries (Taleb and Sharples, 2011; Al-Tamimi, 2017). Studies that have applied the performance-based design approach in hot climates have illustrated that $37 \%$ in annual energy consumption can be achieved when proper envelope systems 


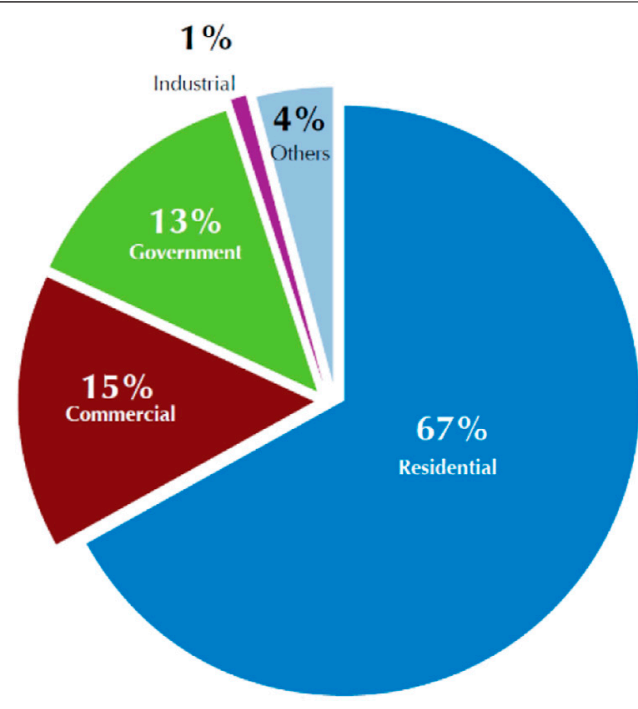

FIGURE 1 | End-use sector distribution of annual electricity consumption in the southern district of KSA.

are implemented (Al-Saadi and Budaiwi, 2007; Taleb and Sharples, 2011). The residential sector in KSA consumes half of the total sold electricity, of which $70 \%$ can be attributed to airconditioning systems to be able to maintain acceptable thermal comfort (SEEC, 2015). Residential consumption dominates all Saudi operating districts, reaching a maximum of $67 \%$ of the total electricity consumption in the Southern Operating District (Figure 1) where this study is carried out (ECRA, 2014).

Common knowledge dictates that avoiding heat gain is the first approach in designing building envelopes, especially in the desert climate of KSA. This approach can help to reduce the transfer of heat from the external harsh environment, especially direct solar radiation and high outdoor temperatures, to the internal spaces of buildings (Alaidroos and Krarti, 2015; Al kanani et al., 2017; El-Darwish and Gomaa, 2017). This study aims to improve the thermal performance and reduce the energy consumption of residential buildings as a result of the envelope's ability to decrease thermal transmittance and solar heat gains. The scope of this work is limited to the evaluation of the influence of building envelope modification on energy consumption of residential buildings in the hot arid climate of Sharurah City, KSA.

This paper describes an investigation of the effect of four passive design strategies, namely, insulation, glazing type, shading devices, and green roof, on the annual energy consumption on a typical residential building being developed and constructed recently in Saudi Arabia. A detailed energy analysis was performed to determine an optimum design for the residential envelope system in Sharurah City, which is located at the edge of the Empty Quarter desert. The paper begins with a general overview of the climate of Sharurah city and then reviews previous research into the use of passive design strategies on residential buildings in similar climates. The model used to simulate the four suggested strategies is then described in the research methodology section, followed by the results and conclusions of the investigation.

\section{CLIMATIC CONDITION OF SHARURAH}

The town of Sharurah lies at $17^{\circ} 47^{\prime} \mathrm{N}$ latitude and $47^{\circ} 08^{\prime} \mathrm{E}$ longitude in the Empty Quarter desert near the Yemeni border at $727 \mathrm{~m}$ above sea level. According to the Saudi Meteorological Authority (KACARE, Summary Report, 2014), the climate of Sharurah is characterised by extreme heat and aridity (Figure 2). During summer, the average temperature ranges from $27.8^{\circ} \mathrm{C}$ to $46.1^{\circ} \mathrm{C}$. The lowest recorded temperature in Sharurah was $-2.2^{\circ} \mathrm{C}$ in January. Annual relative humidity ranges from 9.3 to $39.4 \%$. As a desert climate, Sharurah has virtually no rainfall during the year. The average annual rainfall is $70.29 \mathrm{~mm}$ (Almazroui, 2011). Moreover, amongst KSA cities, Sharurah has the highest daily solar radiation at more than $6.7 \mathrm{kwh} / \mathrm{m}^{2} /$ day (Zell et al., 2015). This heat transfers greatly into the city buildings' internal spaces due to poor thermal performance of building envelopes. This phenomenon produces unacceptable comfort conditions, leading to the increase in airconditioning systems as a means of improving the thermal comfort level of the buildings' users.

\section{PREVIOUS STUDIES}

Gaps in energy efficiency of existing buildings have been raised as common issue around the globe. The energy efficiency framework seems to be a good solution to upgrade the environmental performance of the building sector (Far and Far, 2019). Many studies have investigated the influence of passive design strategies on energy conservation for residential buildings, mainly in hot regions. The literature review in this section covers many studies that had investigated optimum thermal insulation, window glazing, window shading and green roof concepts applied mainly in hot countries.

Most of the related studies have concluded that applying thermal insulation under optimised conditions is an effective approach to energy conservation (Çomaklı and Yüksel, 2003; Dombayc1 et al., 2006; Ucar and Balo, 2010; Yarbrough, 2012; AlSanea et al., 2016; Alsayed and Tayeh, 2019). Huge energy can be saved when a building envelope is properly insulated. Applying thermal insulation on outer surfaces of building envelopes can also significantly reduce annual cooling loads and peak demands. Moreover, the past results also indicate that optimum thickness and payback period depend on climatic conditions regardless of the insulation type. A previous study (Alrashed and Asif, 2014) investigated some of the factors associated with energy consumption in residential buildings, including climatic conditions, housing types, building envelopes and airconditioning systems. The research was based on an analysis of the actual electricity consumption of 115 houses in Dhahran, KSA. The investigated buildings included 62 apartments, 28 villas and 25 traditional houses. The results showed that 50 and $75 \%$ of the apartments and traditional houses were not thermally insulated, respectively. The average 


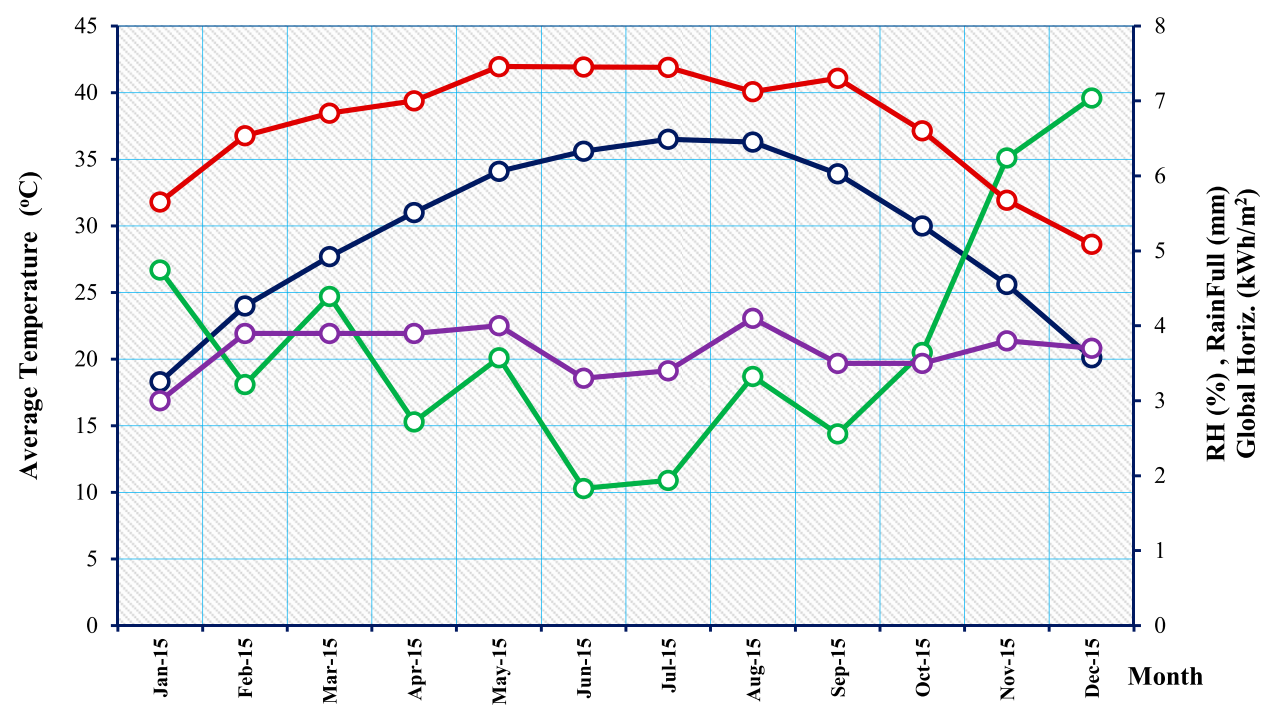

$\longrightarrow$ Avrg. Air Temperature $\left(\mathrm{C}^{\circ}\right)-$ - Avrg. RH (\%) - - Avg Wind Speed (m/s) - Avrg. Global Horiz. $(\mathrm{KWh} / \mathrm{m} 2)$

FIGURE 2 | Sharurah climatic data.

electricity consumption of the dwellings with thermal insulation was approximately $32 \%$ lower than those without thermal insulation. A study (Al-Tamimi, 2021) evaluated the impact of thermal insulation type and its thickness on reducing the energy consumption of a typical villa located in three Saudi cities. The study used DesignBuilder simulation tool to calculate the efficiency of the insulation layers based on the life cycle cost model. The results showed that applying any type of thermal insulation to the walls and ceiling leads to a significant reduction in the total costs. In addition, the highest value for the recovery period was varied between 4.7 and 8.8 years based on the climate condition. Alaidroos et al. (Alaidroos and Krarti, 2015) investigated the impact of building envelope components on the energy saving of residential buildings in five cites in the KSA by using the Energy Plus software. The building envelope measures in the study were walls and roof insulation, window wall ratio, type of glazing, shading devices and thermal mass. Their results showed that significant energy reduction could be obtained for the subsidised energy cost case. The reductions were $39.5,33.7,35,32.7$ and $22.7 \%$ for the buildings located in Riyadh, Jeddah, Dhahran, Tabuk and Abha, respectively. A study (Gondal et al., 2019) conducted to improve the energy efficiency of the buildings by employing passive design strategies and alternative energy resources. MATLAB and TOPSIS software have been employed for this optimization. The study indicated that passive design measures of the building envelope can reduce energy consumption by as much as 33\%. Another study (Aldossary et al., 2014) analyzed the energy consumption patterns in the hot-humid climate of Jeddah. The selected case studies included three typical houses and three typical flats. The collected data were based on monthly electricity bills, user behaviour through interviews and energy simulation, and the IES-VE software was utilised. The aim of the study had been to investigate the impact of shading devices, window glazing and domestic photovoltaic energy sources on energy conservation. On the basis of the simulation results, the past study found that applying design strategies could lead to a reduction in energy consumption in the range of $21-37 \%$. Moreover, the actual data showed that the annual energy consumption in Saudi houses varied between 109 and $185.4 \mathrm{kWh} / \mathrm{m}^{2}$.

Currently, single clear glazing with poorly insulated frames are used in many regions around the world, in which the U-values vary between 4.5 and $5.6 \mathrm{~W} / \mathrm{m}^{2}-\mathrm{K}$ (El-Darwish and Gomaa, 2017). In recent years, major efforts have been adopted to improve the thermal behaviour of glazed windows by using various technologies, such as double glazing, low-emissivity coatings, low-conductivity frames and inert gas fill to be used in residential buildings. According to many studies conducted in hot tropical regions, this approach could reduce the annual cooling load by $7.2 \%$, with a high significant reduction on the peak cooling load reaching 36\% (Al-Tamimi and Fadzil, 2012; Sbar et al., 2012; Aboulnaga et al., 2016; Yu et al., 2020). Another study (Aboulnaga et al., 2016) was conducted by means of retrofitting approach to improve energy performance and mitigate $\mathrm{CO}_{2}$ emission in educational buildings in the hot climate of Cairo, Egypt. The DesignBuilder energy simulation software was used to assess several parameters of the building, including upgrading the glazing with a shading coefficient from 0.81 to 0.35 , a wall of thermal insulation of the building's envelope from 4.8 to $1.15 \mathrm{~W} / \mathrm{K} \mathrm{m}^{2}$ and a green roof. The past results showed that applying those retrofitting measures could reduce energy use by $27 \%$ relative to the base case. A study (Hamid et al., 2016) examined the efficiency of the system called extensive green roof to reduce cooling energy consumption in residential buildings in Riyadh in contrast to the concrete roof system. The past results showed that the use of the green roof system 

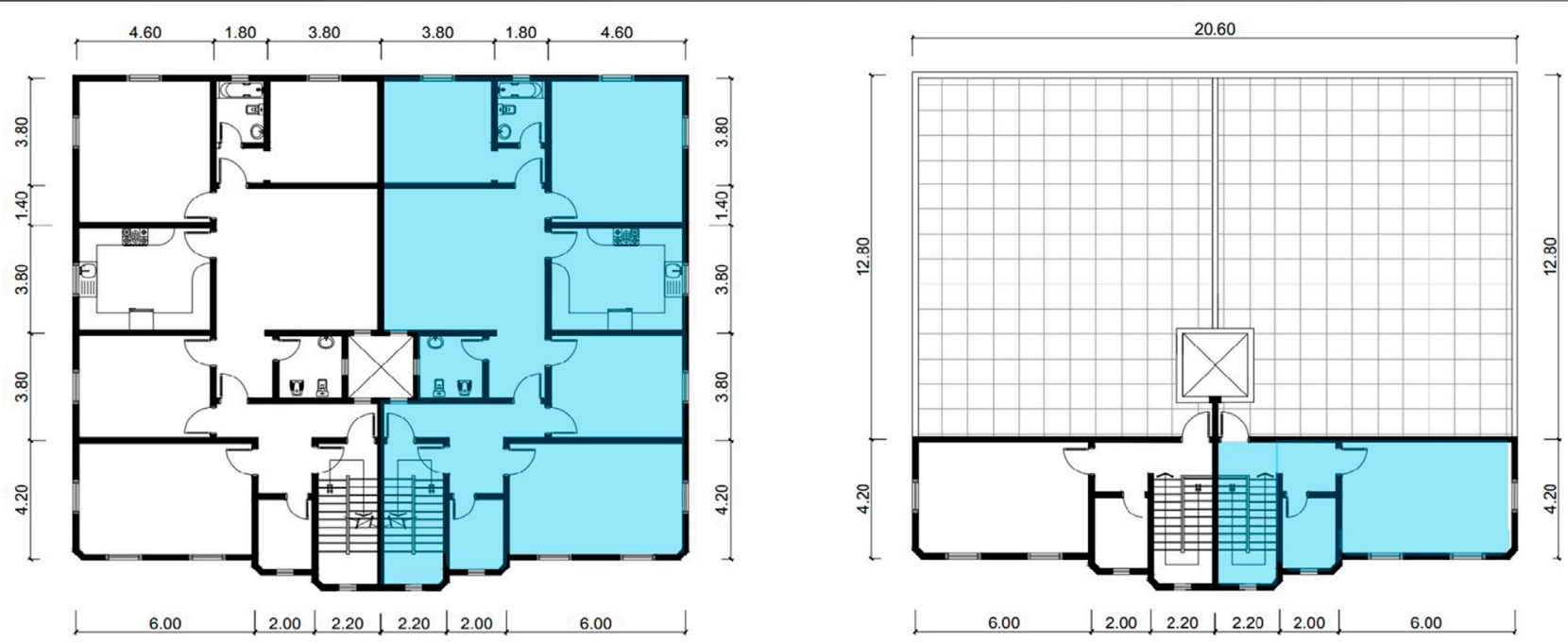

FIGURE 3 | First and second floor plans of the simulated apartment (Author, 2018).

could reduce the energy consumption of airconditioning by 12-33\%. Another study (Goussous et al., 2015) was conducted in a residential building in Jordan to investigate the impact of green roof technology for energy saving. Thermal calculations and computer simulation methods were conducted to compare the regular roof setup with the green roof technology and explore the impact of green roof materials on the thermal transmittance and energy consumption of HVAC systems. Their results showed that $17 \%$ of HVAC energy consumption could be saved with the simplest application of the green roof system.

Generally speaking, previous studies have focused only on a particular envelope component in houses and commercial buildings in moderate, cold or hot humid climates. There is a lack of comparative study of the relative efficiency and impact of passive design strategies. However, the above studies provided resources for this research, such as input parameters and benchmarks for validations that are hard to obtain otherwise. The contribution of this study is merely related to the fact that there have not been similar studies on the specific city located at the Empty Quarter desert, and this work provides a general methodological framework for designing residential buildings. In this sense, the study could be a design template for other residential buildings with similar climate areas in Saudi and Gulf countries.

\section{RESEARCH METHODOLOGY}

Reducing heat gain in buildings located in hot climates is one of the most important approaches to energy reduction. This approach is particularly useful for airconditioning spaces, especially in the summer months. In this study, four passive design strategies in which heat gain affects building envelopes are considered. The four aspects used as basis for the strategies are thermal insulation, glazing type, external shading device and green roof.

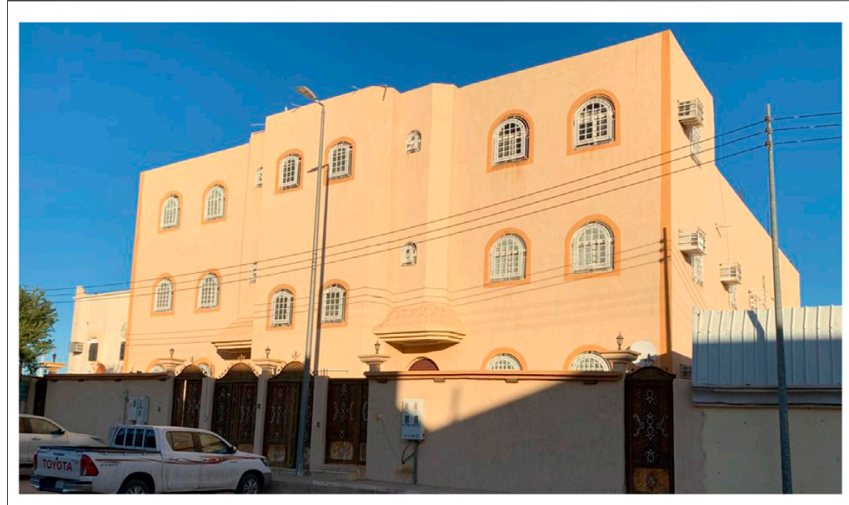

FIGURE 4 | Main elevation of the base case (Author, 2018).

\section{Building Characteristics}

The residential building considered in this study comprises two stories and four apartments. Each apartment has a floor area of $192 \mathrm{~m}^{2}$. Figures 3, 4 illustrates the floor plans and main elevation of the building. The obtained data of the base case (BC) include information related to building material and construction characteristics, schedules of occupancy, house appliances and specifications of the HVAC and the lighting systems used in this building are summarised in Table 1 .

\section{Building Simulation Tool "DesignBuilder"}

Computer-based simulation is a technology used to model accurately design and usage changes (Muller, 2001; Grote and Wang, 2002). In the current research, the rendering of energy models for the prototype was conducted using an hourly building simulation tool called DesignBuilder, which is based on the state-of-the-art building performance simulation software called EnergyPlus (Software, 2016). Figure 5 shows the base case 
TABLE 1 | Building construction, HVAC and lighting systems specifications of the case study.

Characteristics

External wall construction (from outside to inside)

Internal partition construction

Roof construction (from outside to inside)

\section{Description}

$20 \mathrm{~mm}$-thick plaster $200 \mathrm{~mm}$-thick concrete blocks

$20 \mathrm{~mm}$-thick plaster (light)

$20 \mathrm{~mm}$-thick plaster (light)

$150 \mathrm{~mm}$-thick concrete blocks

$20 \mathrm{~mm}$-thick plaster (light)

$20 \mathrm{~mm}$-thick cemented tiles

$15 \mathrm{~mm}$-thick mortar

$50 \mathrm{~mm}$-thick sandstone

$150 \mathrm{~mm}$-thick reinforced concrete

$13 \mathrm{~mm}$-thick plaster (light)

$3 \mathrm{~mm}$-thick single clear

6

$4.0 \mathrm{~W} / \mathrm{m}^{2}$

$3.5 \mathrm{~W} / \mathrm{m}^{2}$

$24^{\circ} \mathrm{C}$

Split DX

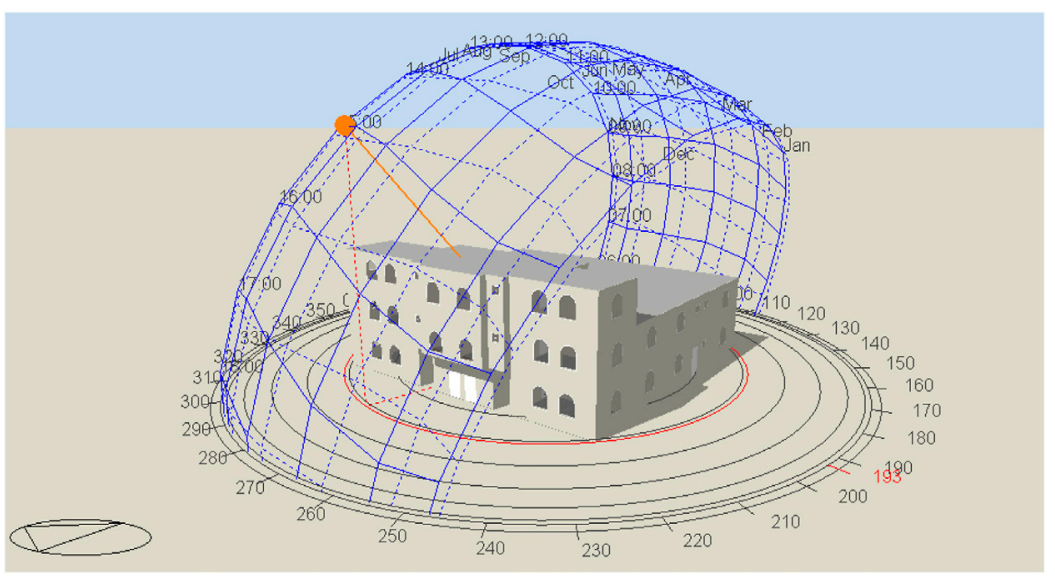

FIGURE 5 | Rendering of the base case model (DesignBuilder v. 6.1.4).

model rendered using the DesignBuilder software. The collected data shows that the total annual energy consumption of the actual $\mathrm{BC}$ is $28,730 \mathrm{kWh}$, which corresponds to an energy use intensity (EUI) of $149.6 \mathrm{kWh} / \mathrm{m} 2 / \mathrm{y}$. Accordingly, the $\mathrm{BC}$ is simulated under the weather file of Sharurah city. A comparison of values between gathered monthly life energy consumption and DesignBuilder DB simulated case was made as shown in Figure 6. After the calibration procedure, the annual energy consumption of the simulated building was $30,180 \mathrm{kWh}$ which corresponds to an (EUI) of $157.19 \mathrm{kWh} / \mathrm{m} 2 / \mathrm{y}$. Thus, the simulated data from the building energy stock model show a good agreement with the actual data with relative errors of approximately $4.8 \%$.

\section{Simulated Cases}

In this paper, the adopted design approach covered four passive design strategies. These strategies aim to enhance energy efficiency in the base case. The effects of each strategy are studied separately. Meaning that when studying the effect of thermal insulation on reducing energy consumption, the rest of the envelope components were fixed to their original state in the base case and so on. However, in the case of the combined alternative, the parameters were selected based on the best results from among the building envelope options presented in each strategy. The subsections below describe strategies adopted according to local climatic conditions.

- Thermal insulation

Thermal insulation materials, such as extruded polystyrene (XPS), has achieved great development in recent years and since has been widely used in insulating the building envelopes of new constructions as part of energy-saving building design requirements ( $\mathrm{Yu}$ et al., 2008). Table 2 lists the layers of the external walls and the roof, dimensions and characteristics of the thermal insulation 


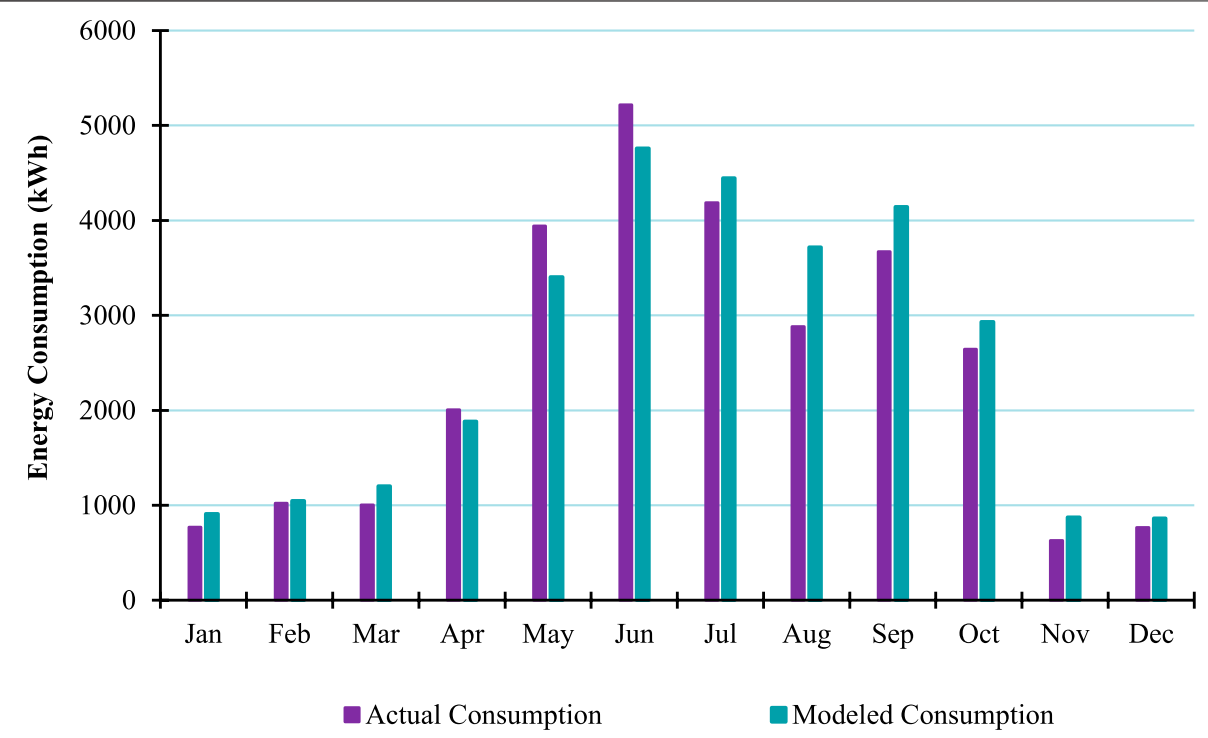

FIGURE 6 | Comparison between actual and simulated monthly energy consumption of the base case.

TABLE 2 | External wall and roof composition with insulation inside the structure.

Code

$\mathrm{BC}$

Walls

Roof
Plaster cement Aerated concrete block XPS Polystyrene Aerated concrete block Plaster (light)

Cemented tiles
Mortar
Sandstone
XPS Polystyrene
Reinforced concrete
Plaster (light)

Thickness (mm)

13

13

13
100
$25 / 50 / 75 / 100$
200
13

20
15
50
$25 / 50 / 75 / 100$
150
13

15

0

0

15
U-value $\left(\mathrm{W} / \mathrm{m}^{2}-\mathrm{k}\right)$

1.478

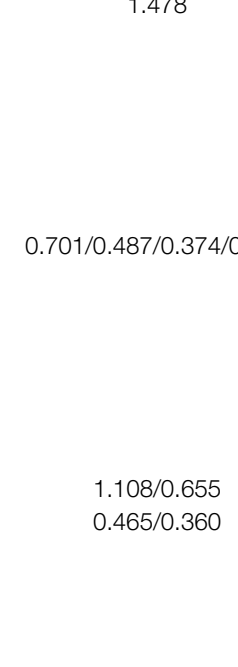

Figure
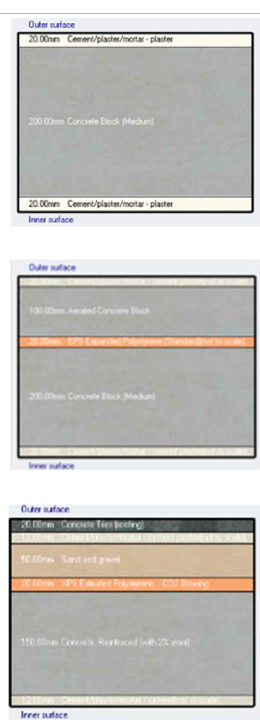

materials used in the simulated case study. The influence of thermal insulation thickness on energy saving was evaluated by increasing the thickness of the XPS insulation material in steps ranging from $25 \mathrm{~mm}$ to a maximum thickness of $100 \mathrm{~mm}$ for the walls and the roof.

\section{- Category of glazed windows}

Energy-saving windows can help to reduce the use of electricity in buildings. In terms of design, choosing the right glass is extremely vital for buildings located in hot arid climates. Many types of glass are currently available in the Saudi market. In this study, the glazing of the base case model was $3 \mathrm{~mm}$ of single clear glass. In addition, five different types of the glazing system were investigated in view of assessing their respectively influence on energy conservation. The glass parameters applied in the DesignBuilder simulation tool and included in the evaluation were glazing thickness, U-value and shading coefficients (Table 3 ).

- Shading Devices 
TABLE 3 | Alternative window compositions.

\begin{tabular}{|c|c|c|c|c|}
\hline Code & Glazing system & Thickness (mm) & U-value $\left(\mathrm{W} / \mathrm{m}^{2}-\mathrm{k}\right)$ & Shading coefficient (SHGC) \\
\hline $\mathrm{BC}$ & Single clear (3 mm) & 3 & 6.257 & 0.858 \\
\hline G1 & Single clear (6 mm) & 6 & 6.121 & 0.810 \\
\hline G2 & Double clear & 3/13 air/3 & 2.761 & 0.761 \\
\hline G3 & Double green & 3/13 air/3 & 2.761 & 0.609 \\
\hline G4 & Triple low-e CLR & 3/13 air/3 & 0.993 & 0.468 \\
\hline G5 & Triple low-e FILM CLR & 6/13 air/6 & 1.223 & 0.355 \\
\hline
\end{tabular}

TABLE 4 | Specification of the modelled shading device.

$\begin{array}{lll}\text { Code Shading description } & \text { Le SHADING } \\ \mathrm{BC} \quad \mathrm{SHADING:} \mathrm{Side} \mathrm{fins} \mathrm{and} \mathrm{overhangs} & \end{array}$

TABLE 5 | Specification of the modelled green roof.

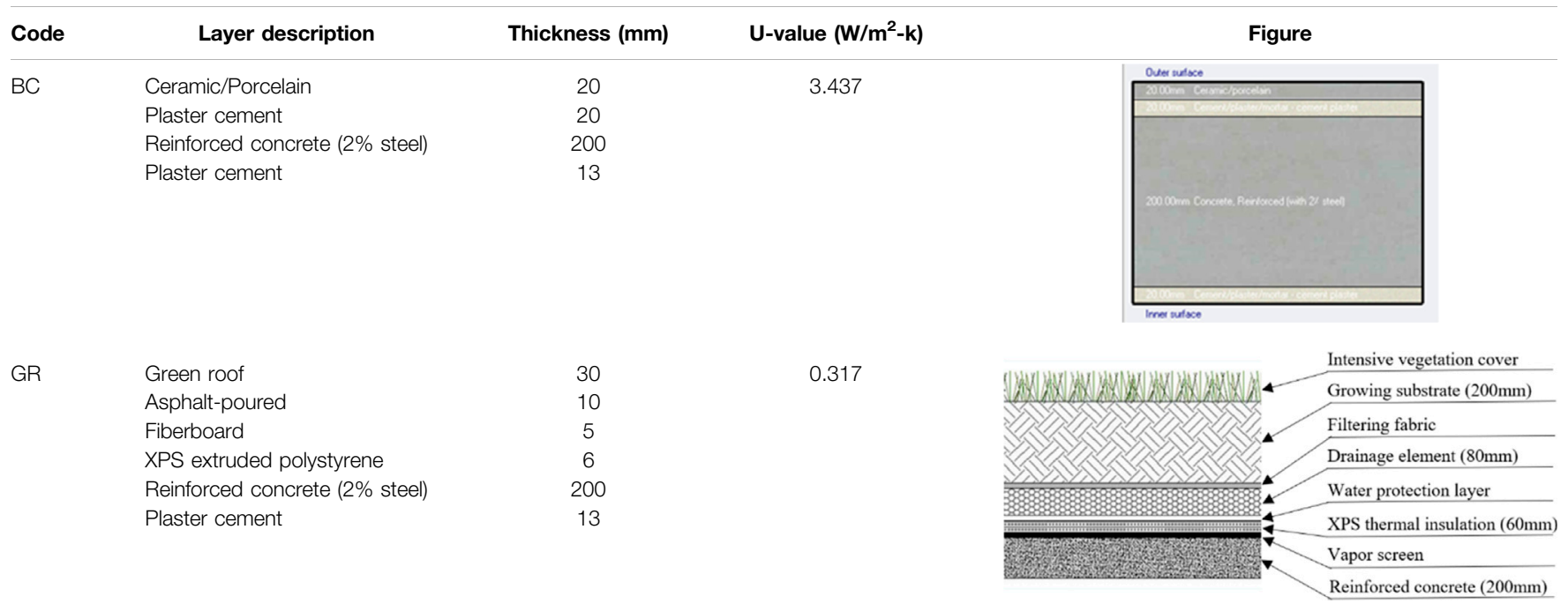

Shading devices are one of the most important principles of environmental design in hot climates with high solar intensity and clear sky. The proper application of shading devices can lead to a substantial reduction in the cooling energy requirements of buildings. The proposed shading devices in this study were a combination of overhangs and fins shading. The length of the horizontal overhang and the vertical fins were set as $60 \mathrm{~mm}$ (Table 4).

- Green roof 


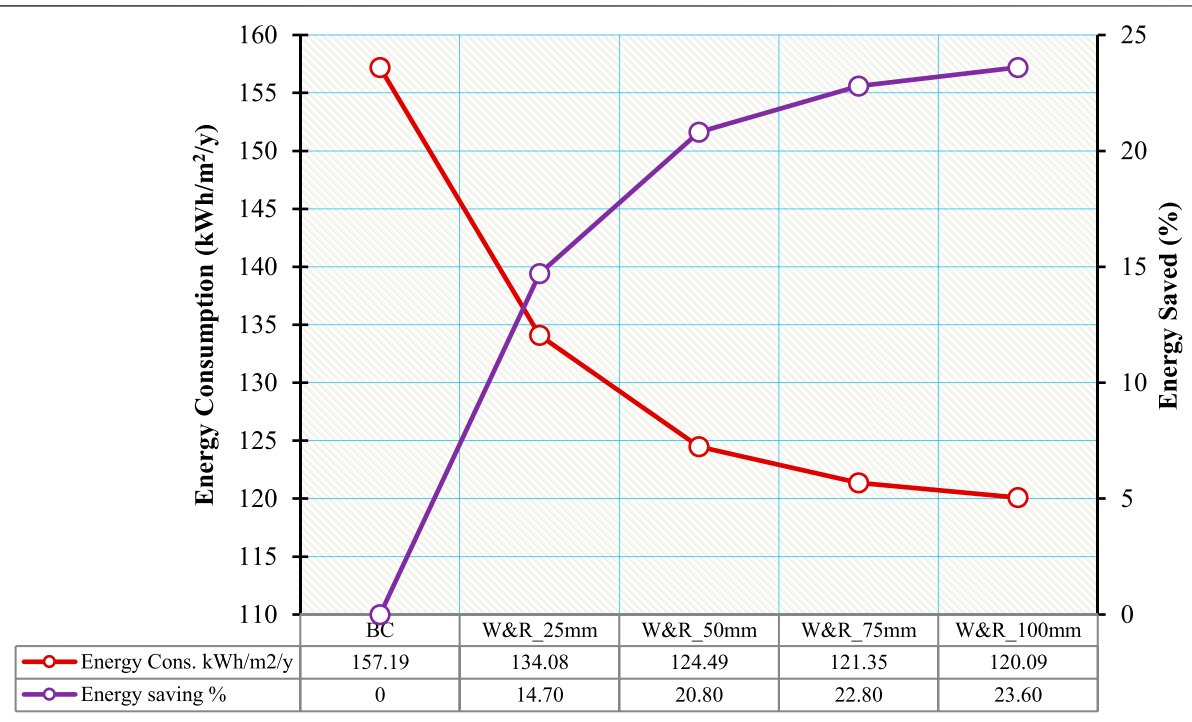

FIGURE 7 | Influence of insulation thickness on energy consumption.

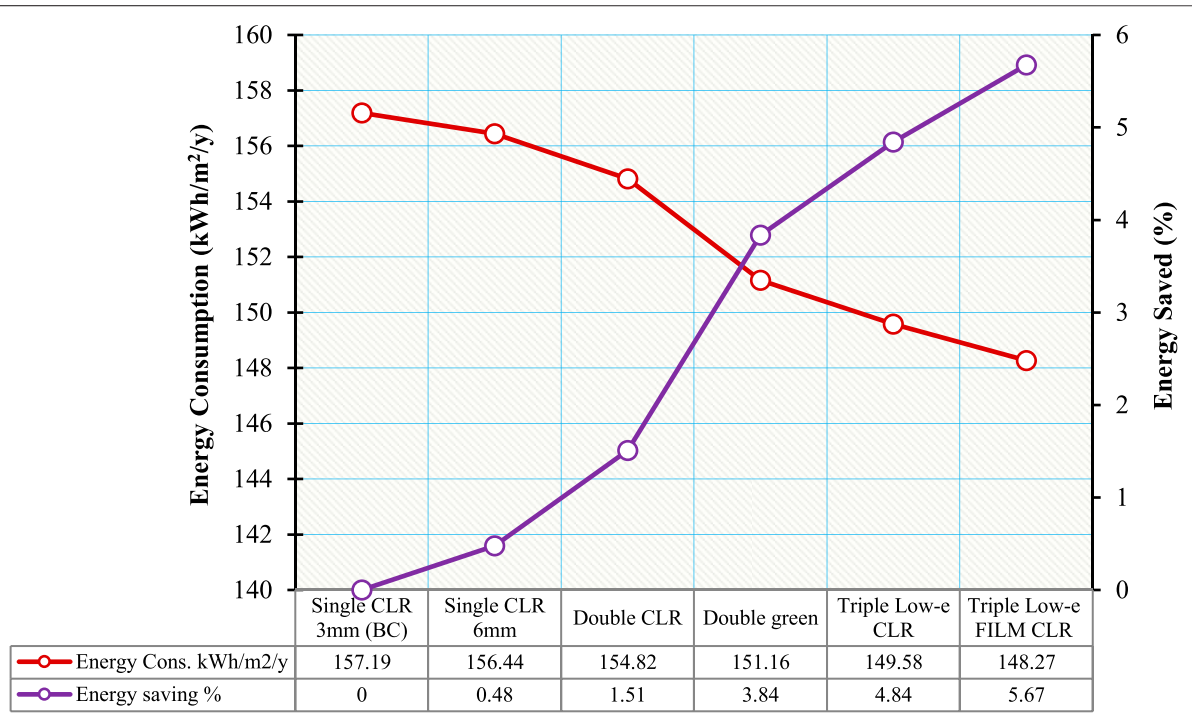

FIGURE 8 | Influence of glazing types on energy consumption.

With a horizontal extension, the roof is one of the main solar heat acquisition points in building (Taleb, 2014). Green roof is a passive strategy that can be regarded a useful solution in different climates owing to their positive contributions in reducing heat gain/loss, thus saving energy consumption in buildings (Goussous et al., 2015; Silva et al., 2016; Khan and Asif, 2017). However, the performance of the green roof depends mainly on the climatic conditions, the building function, the level of insulation of the building envelope and the type of the green roof itself (Hamid et al., 2015). The original roof was composed of traditional construction layers that included a non-insulated roof with a U-value of $3.437 \mathrm{~W} / \mathrm{m}^{2} \mathrm{~K}$. A green roof was implemented on the roofs of the first floor and on the roof of the attached room on the second floor to act as a heat insulator and to take advantage of its ability to lower air temperatures and minimise the airconditioning system requirements. An extensive green roof used to adapt the current roof has a U-value of $0.317 \mathrm{~W} / \mathrm{m}^{2} \mathrm{~K}$, which supported by the current roof structure. Compared with the base case roof, Table 5 shows the layer description of the investigated green roof.

\section{RESULTS AND DISCUSSION \\ Influence of Thermal Insulation in Energy Conservation}

Figure 7 illustrates the influence of thermal insulation thickness on energy conservation when XPS thermal insulation materials are added inside walls and roof (i.e. see Table 3). The figure shows the 
decrease in annual energy consumption $\left(\mathrm{kWh} / \mathrm{m}^{2} / \mathrm{y}\right)$ and percentage of conserved energy. Installing a $25 \mathrm{~mm}$-thick insulation in the middle of the walls and inside the roof layers can significantly reduce the annual energy consumption by $14.4 \%$. Moreover, changing the thickness from $25 \mathrm{~mm}$ to 50 and $75 \mathrm{~mm}$ can reduce the annual energy consumption by 20.3 and $22.8 \%$, respectively. Consequently, a maximum reduction of $23.6 \%$ on annual energy consumption can be achieved by adding $100 \mathrm{~mm}$ of XPS to the main building envelope components (i.e. walls and roof). The results indicate that using thermal insulation thicker than $75 \mathrm{~mm}$ in the hot arid climate of Sharurah is not economical, and extra insulation beyond $75 \mathrm{~mm}$ is ineffective. The best option for the thermal insulation strategy is glazing i.e. application of triple low-e film CLR, as heat transfer is indirectly related to the surface area and inversely related to insulation thickness.

\section{Influence of Glazed Window in Energy Conservation}

Figure 8 illustrates the influence of solar heat gain coefficient (SHGC) and U-value on the annual energy consumption and percentage of saved energy for the modelled apartment. The performance of the five investigated types (i.e., see Table 2) were also compared with the base-case glazing with $3 \mathrm{~mm}$ of single clear glass. Low SHGC glazing can reduce solar heat gains, which is desirable in the hot climate of KSA. Meanwhile, low U-value glazing can reduce the cooling loads for indoor spaces. The results show that when the thickness of the glass in single layer is doubled, i.e. from 3 to $6 \mathrm{~mm}$, the change in energy saving is negligible. However, when the clear glazed window is doubled, it can reduce the heat conduction coefficient, and its energy consumption is lower than that of the single clear glazing by $1.2 \%$. The maximum reduction in the annual energy consumption can reach $5.2 \%$ when the $\mathrm{BC}$ glazing system is replaced with triple low-e film glass. Moreover, when the layers of the glass are increased, the energy reduction effect also increases regardless of the level of glass transparency.

\section{Influence of Shading Devices in Energy Conservation}

Shading devices plays a major role in reducing the energy consumption of buildings, especially in the desert climate where global radiation is high. However, exterior shading requires more thought and innovative design because of the unlimited choices of materials, types, shapes, dimensions, orientation, external visualisation and performance at varying Sun angles. According to the efficient shading devices mentioned in the literature, one of the options was simulated in this research to assess the performance of the external shading device. In the selected option, an aluminium material with vertical fins and horizontal overhang at a depth of $60 \mathrm{~cm}$ was assessed. The simulation results indicate the considerable effect of shading devices on energy consumption. The shading devices could reduce the annual energy consumption from 157.19 to $146.86 \mathrm{kWh} / \mathrm{m}^{2} / \mathrm{y}$, with a reduction rate of approximately $6.57 \%$. As previously shown in Figure 3, the climatic data used in the analysis presented an average global solar radiation of 7.5 and $5.1 \mathrm{~kW} / \mathrm{m}^{2}$ in summer and winter, respectively. Sharurah experiences high solar radiation, leading to high solar heat gains penetrating through glazed windows. In this study, the influence of the shading devices was not significant in general because of the low window-to-wall ratio of $6.4 \%$. However, this reduction can be considered high when the impact of shading devices on cooling loads only is considered.

\section{Influence of Green Roof Materials in Energy Conservation}

On hot days, green roofs can reduce heat flux in indoor space and airconditioning energy usage (Jim, 2014). The green roof strategy in this study was used to simulate the amount of reduction in annual energy consumption. The results indicate that green roofs in hot arid climate can considerably reduce the annual energy consumption from 157.19 to $144.80 \mathrm{kWh} / \mathrm{m}^{2} / \mathrm{y}$, with a reduction of approximately $7.88 \%$. In a hot desert climate, the water content in green roofs can significantly reduce the transferred heat to the interior space, yet it represents high structural loads and requires continuous operational cost and maintenance. From this standpoint and on the basis of the simulation results, the percentage of reduced energy consumption by means of the green roof strategy is ineffective. However, the green roof strategy's impact at the environmental level and its capability to improve air quality, enhance relative humidity and reduce carbon dioxide emissions render it an extremely important endeavour. Thus, green roofs should be designed properly based on the characteristics of the climatic condition, as location, temperature, humidity, precipitation rate, availability of water and wind will affect the design of green roofs.

\section{Influence of Combination Strategy in Energy Conservation}

The parameters of building envelope design were evaluated to analyze the impact of individual design replacements and the combined effect of envelope design parameters on annual total energy consumption. In Influence of Thermal Insulation in Energy Conservation, Influence of Glazed Window in Energy Conservation, Influence of Shading Devices in Energy Conservation, Influence of Green Roof Materials in Energy Conservation, the impact of thermal insulation, glazing type, shading device and green roof strategies on energy consumption have been studied separately. In view of providing a thermally comfortable environment, sound combinations of certain variables (Table 6) need to be determined. The design alternatives were selected on the basis of the best results amongst the building envelope options presented in the previous sections. However, the green roof strategy was excluded in the combination solution due to its high cost of installation, maintenance and continuous monitoring vis the level of its performance in reducing energy consumption; this strategy was replaced accordingly by another roofing system with a layer of $75 \mathrm{~mm}$ of XPS thermal insulation. The simulation results indicate that a maximum of $35.39 \%$ of 
TABLE 6 | Alternative designs for the combination case compared with the base case.

\begin{tabular}{|c|c|c|}
\hline Type & Base case & Optimum cases \\
\hline Type of glass & Single clear $3 \mathrm{~mm}$ & Triple low-e CLR 6 mm/13 mm Air \\
\hline \multirow[t]{5}{*}{ External wall construction layers } & Plaster cement (13 mm) & Plaster cement (13 mm) \\
\hline & Concrete block (200 mm) & Aerated concrete block (100 mm) \\
\hline & Plaster cement (13 mm) & XPS polystyrene $(75 \mathrm{~mm})$ \\
\hline & & Aerated concrete block (200 mm) \\
\hline & & Plaster (light) (13 mm) \\
\hline \multirow[t]{6}{*}{ Roof construction layers } & Ceramic/porcelain (20 mm) & Cemented tiles (20 mm) \\
\hline & Plaster cement (15 mm) & Mortar (15 mm) \\
\hline & Reinforced concrete (200 mm) & Sandstone (50 mm) \\
\hline & Plaster cement (13 mm) & XPS polystyrene (75 mm) \\
\hline & & Reinforced concrete (150 mm) \\
\hline & & Plaster (light) (13 mm) \\
\hline Type of shading & No Shading & - Side fins (600 mm) \\
\hline & & - Overhangs (600 mm) \\
\hline Energy consumption (Kwh/m²/y) & 157.19 & 101.56 \\
\hline Energy saving \% & 0.00 & 35.39 \\
\hline
\end{tabular}

annual energy consumption can be achieved when the combination strategy is applied.

\section{CONCLUSION}

Information about the selected case study was collected to study the energy performance of residential buildings in the south region of KSA. The DesignBuilder simulation tool was used to model the case. The energy efficiency enhancement of the building envelope was assessed by changing the glazing type, applying different types of thermal insulations and evaluating the green roof strategy and using shading devices. On the basis of the analytical results of this research, the following conclusion are drawn for the energyefficient design of existing homes and for newly designed or constructed residential buildings:

- Amongst the other investigated glass types, this study recommends the use of triple low-e FILM CLR mm/13 mm/ $6 \mathrm{~mm}$ glass for the glazed windows of residential buildings. This type has good light transmission with a low U-value of $1.22 \mathrm{~W} / \mathrm{m}^{2}-\mathrm{k}$, and it can reduce the energy usage in residential buildings by $5.15 \%$

- This research highly recommends the use of a $25 \mathrm{~mm}$-thick thermal insulation layer to effectively reduce the annual energy consumption by at least $14.7 \%$.

- Shading devices have a remarkable impact on energy saving. Aluminium devices in vertical and horizontal forms with $60 \mathrm{~cm}$ depth can lead to $6.6 \%$ reduction in energy consumption, as these materials can avoid solar radiation from varying Sun angles.

\section{REFERENCES}

Aboulnaga, M., Wanas, A., Hammad, M., and Hussein, M. (2016). Sustainability of Higher Educational Buildings: Retrofitting Measures to Enhance Energy Performance-The
- The green roof strategy is slightly more effective than the other strategies except for the thermal insulation strategy in the hot-dry climate of Sharurah. Green roofs can reduce annual energy consumption by $7.9 \%$. However, the maintenance of the required waterproofing membranes is complicated. A green roof system requires complete coverage of its membrane, yet leaks can still occur at the joints. Regular maintenance inspections should be scheduled as part of the standard roof installation.

- A combination of different passive design strategies can help to significantly reduce annual energy consumption by $35.4 \%$. - The proper design of building envelopes can considerably improve the thermal performance of residential buildings. Therefore, designers and developers are highly encouraged to use this study when applying a combination of passive design elements to residential building envelope components in countries with hot arid climates, thus enabling them to achieve energy-efficient designs.

\section{DATA AVAILABILITY STATEMENT}

The original contributions presented in the study are included in the article/Supplementary Material, further inquiries can be directed to the corresponding author.

\section{AUTHOR CONTRIBUTIONS}

The author confirms being the sole contributor of this work and has approved it for publication.

Case of AASTMT Business Management School Building, Egypt. Mediterr. Green Buildings Renew. Energ. 1, 117-150. doi:10.1007/978-3-319-30746-6_9

Al kanani, A., Dawood, N., and Vukovic, V. (2017). "Energy Efficiency in Residential Buildings in the Kingdom of Saudi Arabia," in Building Information Modelling, Building Performance, Design and Smart Construction. Editors M. Dastbaz, 
C. Gorse, and A. Moncaster (Cham: Springer International Publishing), 129-143. doi:10.1007/978-3-319-50346-2_10

Al-Saadi, S. N., and Budaiwi, I. M. (2007). "Performance Based Envelope Design for Residential Buildings in Hot Climates," in Proceedings of Building Simulation 2007 (Beijing, China.

Al-Sanea, S. A., Zedan, M. F., Al-Mujahid, A. M., and Al-Suhaibani, Z. A. (2016). Optimum R-Values of Building walls under Different Climatic Conditions in the Kingdom of Saudi Arabia. Appl. Therm. Eng. 96, 92-106. doi:10.1016/ j.applthermaleng.2015.11.072

Al-Tamimi, N. (2017). A State-Of-The-Art Review of the Sustainability and Energy Efficiency of Buildings in Saudi Arabia. Energy Efficiency 10 (5), 1129-1141. doi:10.1007/s12053-017-9507-6

Al-Tamimi, N. (2021). An Optimum Thermal Insulation Type and Thickness for Residential Buildings in Three Different Climatic Regions of Saudi Arabia. cea 9 (2), 317-327. doi:10.13189/cea.2021.090205

Al-Tamimi, N., and Fadzil, S. F. S. (2012). Energy-efficient Envelope Design for High-Rise Residential Buildings in Malaysia. Architectural Sci. Rev. 55 (2), 119-127. doi:10.1080/00038628.2012.667938

Alaidroos, A., and Krarti, M. (2015). Optimal Design of Residential Building Envelope Systems in the Kingdom of Saudi Arabia. Energy and Buildings 86, 104-117. doi:10.1016/j.enbuild.2014.09.083

Aldossary, N. A., Rezgui, Y., and Kwan, A. (2014). Domestic Energy Consumption Patterns in a Hot and Humid Climate: A Multiple-Case Study Analysis. Appl. Energ. 114, 353-365. doi:10.1016/j.apenergy.2013.09.061

Almazroui, M. (2011). Calibration of TRMM Rainfall Climatology over Saudi Arabia during 1998-2009. Atmos. Res. 99 (3), 400-414. doi:10.1016/ j.atmosres.2010.11.006

Alrashed, F., and Asif, M. (2014). Trends in Residential Energy Consumption in Saudi Arabia with Particular Reference to the Eastern Province. J. Sustain. Dev. Energy Water Environ. Syst. 2 (4), 376-387. doi:10.13044/j.sdewes.2014.02.0030

Alsayed, M. F., and Tayeh, R. A. (2019). Life Cycle Cost Analysis for Determining Optimal Insulation Thickness in Palestinian Buildings. J. Building Eng. 22, 101-112. doi:10.1016/j.jobe.2018.11.018

Asfour, O. S. (2020). A Comparison between the Daylighting and Energy Performance of Courtyard and Atrium Buildings Considering the Hot Climate of Saudi Arabia. J. Building Eng. 30, 101299. doi:10.1016/j.jobe.2020.101299

Çomakl, K., and Yüksel, B. (2003). Optimum Insulation Thickness of External walls for Energy Saving. Appl. Therm. Eng. 23 (4), 473-479.

Dombayc1, Ö. A., Gölcü, M., and Pancar, Y. (2006). Optimization of Insulation Thickness for External walls Using Different Energy-Sources. Appl. Energ. 83 (9), 921-928.

ECRA (2014). Annual Statistical Booklet for Electricity \& Seawater Desalination Industries. KSA: Electricity and Cogeneration Regulatory Authority.

EIA. Independent (2014). Statistics and Analysis: Annual Energy Outlook 2014. US Energy Information Administration. Available at: http://www.eia.gov/forecasts/ aeo/er/(Accessed Dec 26, 2015).

El-Darwish, I., and Gomaa, M. (2017). Retrofitting Strategy for Building Envelopes to Achieve Energy Efficiency. Alexandria Eng. J. 56 (4), 579-589. doi:10.1016/ j.aej.2017.05.011

Far, C., and Far, H. (2019). Improving Energy Efficiency of Existing Residential Buildings Using Effective thermal Retrofit of Building Envelope. Indoor Built Environ. 28 (6), 744-760. doi:10.1177/1420326x18794010

GAS (2019). Statistical Yearbook, General Authority of Statistics. KSA: Riyadh.

GAStat, Annual Report 2018, the General Authority for Statistics. 2019: Available at: https://www.stats.gov.sa [Accessed: 07 Oct 2019].

Gondal, I. A., Syed Athar, M., and Khurram, M. (2019). Role of Passive Design and Alternative Energy in Building Energy Optimization. Indoor Built Environ. 0 (0), 1420326X19887486. doi:10.1177/1420326x19887486

Goussous, J., Siam, H., and Alzoubi, H. (2015). Prospects of green Roof Technology for Energy and thermal Benefits in Buildings: Case of Jordan. Sust. Cities Soc. 14, 425-440. doi:10.1016/j.scs.2014.05.012

Grote, L., and Wang, D. (2002). Architectural Research Methods. New York: John Wiley \& Sons. Print in the United tastes of America.
Hamid, A., Roozbeh, A., and Leyla, F. (2015). Thermal Behavior of Green Roofs in Different Climates. Curr. World Environ. 10 (1), 908-917. doi:10.12944/cwe.10.special-issuel.110

Hamid, A., Roozbeh, A., and Leyla, F. (2016). Thermal Performance of the Extensive Green Roofs in Hot Dry Climate. Int. J. Adv. Eng. Res. Sci. 3 (5), 85-94.

Jim, C. Y. (2014). Air-conditioning Energy Consumption Due to green Roofs with Different Building thermal Insulation. Appl. Energ. 128, 49-59. doi:10.1016/j.apenergy.2014.04.055

KACARE, Summary Report (2014). Solar and Meteorological Data, King Abdullah City for Atomic and Renewable Energy, the Data Is Calculated from November 01. to May 31, 2017. 2019.

Khan, H., and Asif, M. (2017). Impact of Green Roof and Orientation on the Energy Performance of Buildings: A Case Study from Saudi Arabia. Sustainability 9 (4), 640. doi:10.3390/su9040640

Muller, E. (2001). "Development of A Test Reference Year on A Limited Data Base for Simulations on Passive Heating and Cooling in Chile," in Proceedings of IBPSA Conference: Building Simulation, Rio de Janeiro, Brazil.

Sbar, N. L., Podbelski, L., Yang, H. M., and Pease, B. (2012). Electrochromic Dynamic Windows for Office Buildings. Int. J. Sust. Built Environ. 1 (1), 125-139. doi:10.1016/j.ijsbe.2012.09.001

SEEC, Energy Efficiency in KSA: Saudi Energy Efficiency Center, Annual Report 2014. 2015: Available at: http://www.seec.gov.sa [Accessed: 06-Jan-2016].

Silva, C. M., Gomes, M. G., and Silva, M. (2016). Green Roofs Energy Performance in Mediterranean Climate. Energy and Buildings 116, 318-325. doi:10.1016/ j.enbuild.2016.01.012

Software, D. (2016). User Manual.

Taleb, H. M., and Sharples, S. (2011). Developing Sustainable Residential Buildings in Saudi Arabia: A Case Study. Appl. Energ. 88 (1), 383-391. doi:10.1016/ j.apenergy.2010.07.029

Taleb, H. M. (2014). Using Passive Cooling Strategies to Improve thermal Performance and Reduce Energy Consumption of Residential Buildings in U.A.E. Buildings. Front. Architectural Res. 3 (2), 154-165. doi:10.1016/j.foar.2014.01.002

Ucar, A., and Balo, F. (2010). Determination of the Energy Savings and the Optimum Insulation Thickness in the Four Different Insulated Exterior walls. Renew. Energ. 35 (1), 88-94. doi:10.1016/j.renene.2009.07.009

Yarbrough, D. W. (2012). "Thermal Insulation for Energy Conservation," in Handbook of Climate Change Mitigation. Editor W. Y. Chen, J. Seiner, T. Suzuki, and M. Lackner (New York, NY: Springer US), 649-668. doi:10.1007/978-1-4419-7991-9_19

Yu, C.-R., Guo, H. S., Wang, Q. C., and Chang, R. D. (2020). Revealing the Impacts of Passive Cooling Techniques on Building Energy Performance: A Residential Case in Hong Kong. Appl. Sci. 1010 (124188), 1-24. doi:10.3390/app10124188

Yu, J., Yang, C., and Tian, L. (2008). Low-energy Envelope Design of Residential Building in Hot Summer and Cold winter Zone in China. Energy and Buildings 40 (8), 1536-1546. doi:10.1016/j.enbuild.2008.02.020

Zell, E., Gasim, S., Wilcox, S., Katamoura, S., Stoffel, T., Shibli, H., et al. (2015). Assessment of Solar Radiation Resources in Saudi Arabia. Solar Energy 119, 422-438. doi:10.1016/j.solener.2015.06.031

Conflict of Interest: The author declares that the research was conducted in the absence of any commercial or financial relationships that could be construed as a potential conflict of interest.

Publisher's Note: All claims expressed in this article are solely those of the authors and do not necessarily represent those of their affiliated organizations, or those of the publisher, the editors, and the reviewers. Any product that may be evaluated in this article, or claim that may be made by its manufacturer, is not guaranteed or endorsed by the publisher.

Copyright $\odot 2022 \mathrm{Al}$-Tamimi. This is an open-access article distributed under the terms of the Creative Commons Attribution License (CC BY). The use, distribution or reproduction in other forums is permitted, provided the original author $(s)$ and the copyright owner(s) are credited and that the original publication in this journal is cited, in accordance with accepted academic practice. No use, distribution or reproduction is permitted which does not comply with these terms. 